\title{
NBSIR 74-502 ( (R) \\ The Determination of Iodine-129 at Natural Levels Using Neutron Activation and Isotopic Separation
}

Harry L. Rook, James E. Suddueth, Donald A. Becker

Analytical Chemistry Division

Institute for Materials Research

National Bureau of Standards

Washington, D. C. 20234

January 1974

Final Report

Prepared for

Defense Advanced Research Projects Agency

Arlington, Virginia 22209

ARPA Order 1702 



\section{THE DETERMINATION OF IODINE-129 AT \\ NATURAL LEVELS USING NEUTRON \\ ACTIVATION AND ISOTOPIC SEPARATION}

Harry L. Rook, James E. Suddueth, Donald A. Becker

Analytical Chemistry Division

Institute for Materials Research

National Bureau of Standards

Washington, D. C. 20234

January 1974

Final Report

Prepared for

Defense Advanced Research Projects Agency

Arlington, Virginia 22209

ARPA Order 1702

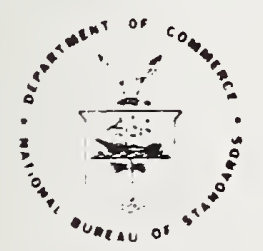

U. S. DEPARTMENT OF COMMERCE, Froderick B. Dent, Secretary

NATIONAL BUREAU OF STANDARDS, Richard W. Roberts, Director 


\section{THE DETERMINATION OF ${ }^{129}$ I AT NATURAL LEVELS USING NEUTRON ACTIVATION AND ISOTOPIC SEPARATION}

by

Harry L. Rook, James E. Suddueth, and Donald A. Becker Analytical Chemistry Division

National Bureau of Standards

Washington, D.C. 20234

\section{ABSTRACT}

Iodine-129 levels have been published for biological matrices that naturally accumulate iodine such as animal thyroid and kelp. However, published procedures have insufficient sensitivity to determine ${ }^{129} \mathrm{I}$ in other environmental and biological species. A unique procedure has been developed for the determination of ${ }^{129} \mathrm{I}$ which couples neutron activation with mass separation. The procedure results in a significant improvement in sensitivity, thus allowing analyses to be performed on a variety of matrices which heretofore had not been investigated. Method development and analytical procedures are presented and analytical results at the $10^{-13}-10^{-14} \mathrm{gram}{ }^{129} \mathrm{I}$ level are given.

Key Words: Iodine-129; isotopic separation; neutron activation. 
1. Introduction . . . . . . . . . . . . . . 1

1.1 Background . . . . . . . . . . . . . 1

1.2 Purpose. . . . . . . . . . . . 2

2. Experimental . . . . . . . . . . . . 3

2.1 Mass Separator .......... . 3

2.2 Preseparation . . . . . . . . . 6

2.3 Irradiation . . . . . . . . . . . 7

2.4 Post-Irradiation Separation . . . . . . 7

2.5 Counting . . . . . . . . . . 10

2.6 Standards . . . . . . . . . . . 11

3. Results and Discussion . . . . . . . . . 11

3.1 Quantitation ............ 11

3.2 Analytical . . . . . . . . . . . 13

3.3 Interferences and Errors . . . . . . 15

4. Conclusions and Proposed Research . . . . . 18

Bibliography . . . . . . . . . . . . 20 
Table No.

1. Mass Separator Yield as a Function of Arc Current . . . . . . . . . 21

2. Separation Yields as a Function of Mass . . 22

3. System Blank for Normal Laboratory Operation . . . . . . . . . 22

4. ${ }^{129}$ I Analytical Results . . . . . . . 23 
FIGURE NO.

1. Backloading Assemb1y . . . . . . . . . 24

2. Modified Backloader and Furnace . . . . . 25

3. Beam Collector Plate... . . . . . . 26

4. Sample Combustion System . . . . . . . 27

5. Modified Backloader Boat . . . . . . . 28

6. Collector Foil with B Scintillator. . . . . 29 


\section{THE DETERMINATION OF ${ }^{129}$ I AT NATURAL LEVELS USING NEUTRON ACTIVATION AND ISOTOPIC SEPARATION}

Harry L. Rook, James E. Suddueth, and Donald A. Becker Analytical Chemistry Division

National Bureau of Standards

Washington, D.C. 20234

\section{INTRODUCTION}

$1.1 \quad$ Background

Iodine-129 is a nuclide of considerable interest. It is produced in trace quantities by natural processes and has a half 1 ife of $1.59 \times 10^{7}$ years, thus, a steady state concentration of ${ }^{129}$ I had been established in the biosphere prior to the advent of the nuclear age. Since that time, its concentration is believed to be steadily increasing. For health and safety reasons, as well as nuclear monitoring, a reliable method for determining ${ }^{129}$ I concentrations in biological and ecological matrices is of great interest.

Due to the long half 1 ife of ${ }^{129}$ I, low level counting techniques are not normally sensitive enough to enable its direct determination at natural levels. Purkayastha and Martin first reported a procedure to enhance the sensitivity of the determination by neutron irradiation (1). Samples were irradiated in a high flux reactor and the 12.5 hour half 1 ife ${ }^{130}$ I product was counted. By combining this procedure with radiochemical separations for iodine, numerous authors have reported ${ }^{129}$ I sensitivities in the $10^{-9}-10^{-11}$ gram range $(2-7)$. 
However, ${ }^{130} \mathrm{I}$ is subject to several possible interferences. These include direct production by the ${ }^{133} \mathrm{Cs}(\mathrm{n}, \alpha)^{130} \mathrm{I}$ and indirect production by the ${ }^{127} \mathrm{I}(3 \mathrm{n}, \gamma)^{130} \mathrm{I}$ and the ${ }^{235} \mathrm{U}(\mathrm{n}, \mathrm{f}){ }^{129}$ I reactions. The above procedures eliminated direct production interference by pre-irradiation chemical separations and from numerous other trace activities by postirradiation chemical separations. However, the following three secondary reactions could not be eliminated and all authors used only the high energy photon of ${ }^{130} \mathrm{I}$ for discrimination from other iodine isotopes. These reactions are: a) ${ }^{126}$ I produced via an $(n, 2 n)$ reaction on natura 1 ${ }^{127} \mathrm{I}$; b) iodine fission products of ${ }^{235} \mathrm{U}$, exclusive of shielded ${ }^{130} \mathrm{I}$; and c) neutron capture products of ${ }^{128} \mathrm{Te}$ and $130_{\mathrm{Te}}$. As an added complication, bromine-82 offered a significant problem in all of the separation procedures due to its similar chemistry to that of iodine. As a result, all previously published procedures do not have the sensitivity to determine ${ }^{129} \mathrm{I}$ in most environmental matrices (7) .

\subsection{Purpose}

This work was undertaken to demonstrate the feasibility of using a mass separator to lower the detection limit for the determination of ${ }^{129} \mathrm{I}$. It can be calculated that if ${ }^{129} \mathrm{I}$ is separated free of other radioactivity, less than $10^{-14}$ grams of ${ }^{129} \mathrm{I}$ can be detected using low level $\beta-\gamma$ coincidence sum counting techniques. Mass separation is an extremely important tool as it offers the only means of separating ${ }^{130} \mathrm{I}$ from other iodine isotopes in the irradiation products. This fact, plus the virtual elimination of other radioactive contaminants accounts for the improved sensitivity. The use of an electromagnetic mass separator to effect simple, interference-free separations in activation analysis has been demonstrated (8). 
In this project, the total analytical procedure for the quantitative analysis of ${ }^{129} \mathrm{I}$ was reviewed and improved wherever possible:

- a revised preseparation of total iodine was developed based on sample combustion and quantitative isolation of iodine.

- a substantial reduction of system blank was demonstrated by operation in a class 100 clean room;

- a design change was made on the mass separator which resulted in substantially improved yields;

- the mass separator operation was optimized and data obtained on yields, intermass contamination and memory;

- an improved procedure for $\beta-\gamma$ coincidence counting was devised where the ${ }^{1{ }^{30}} \mathrm{I}$ was directly implanted into thin B scintillators;

- finally, real samples were run to give a realistic estimate of the detection limit, blank level and its variations, and levels of ${ }^{129} \mathrm{I}$ in selected environmental matrices.

\section{EXPERIMENTAL}

\subsection{Mass Separator}

Al1 work was performed using a Harwell designed electromagnetic mass separator manufactured by Lintott Engineering, Ltd.* (9). The separator uses a standard Harwell ion source containing a hot cathode arc chamber with a $4 \mathrm{~cm}$ extraction slit. The extraction potential is variable from 0 to $40 \mathrm{kV}$, with the beam focused using conventional ion beam optics. The mass separation takes place in a $60^{\circ}, 0.4$ m radius,

*See Disclaimer 
homogeneous-field analyzing magnet. The magnet is fitted with wide pole-tips with rotatable inserts so that its cffective deflecting radius is adjustable with respect to the center of curvature. The combination of these adjustments permits considerable variation in the geometry of the analyzing magnet and allows the focal length, dispersion, and divergence of the ion beam to be controlled over wide limits.

$\Lambda$ llarwell designed backloading assembly was incorporated with one ion source so that solid samples could be introduced into a resistance-wire heated oven and vaporized directly into the arc chamber (Figure 1 ). The over has a dynamic range of 20 to $1200{ }^{\circ} \mathrm{C}$. The backloading system was designed with a minimum dead volume thereby minimizing pumpdown and outgassing time; a sample can be introduced into the separator and be ready for operational startup within 15 minutes.

The backloading assembly, as designed, had considerably lower efficiencies ( $(0.5-5 \%$ ) and higher memory (up to $\sim 4 \%$ ) than the conventional closed oven. The loss in efficiency and increase in memory was most obvious with metals such as tin, lead and cadmium. Close examination of radioactive tracers condensed inside the ion source after a run indicated that a large portion of the vaporized sample was escaping from the rear of the oven and condensing onto cooler metal parts. This material was then vaporized and introduced into the beam during subsequent runs.

The backloading assembly has been modified so that the graphite sample container makes a seal with a conical boron nitride insert placed in the front of the oven. The opening 
leading to the arc chamber has been increased from 0.228 to $0.635 \mathrm{~cm}$ diameter (Figure 2). The net effect of these modifications has been to introduce virtually all of the vaporized sample directly into the arc chamber. This modification has doubled separation yields to $\sim 10 \%$ and simultaneously reduced the memory to the $10^{-2}-10^{-3} \%$ evel. Yields are defined here as the percent of collected isotope compared to the quantity of input isotopic material. Improvement of the backloader is important, since without it the ion source must be removed from the machine for reloading of samples requiring lengthy pump down and degassing procedures.

A second, and even more dramatic improvement in yield was achieved by a modification of the ion source power supply. A circuit modification was made to allow stable operation at higher arc currents. This, in turn, caused a higher ionization efficiency in the arc chamber. Before the modification, the maximum stable arc current obtainable was 2.0 amps. Now, arc currents of up to 5 amps can be routinely used. It was noted from collector current readings that the beam intensity increased proportionally with increasing arc current up to about 4.5 amps. Subsequent tracer runs have verified this with optimum yields at 4.2 amps of arc current. Results of yield improvements subsequent to the instrument modifications are given in Table 1.

The collection plate is a two-stage, movable, water cooled graphite plate with a vertically centered slit $1 \mathrm{~mm}$ wide and $4 \mathrm{~cm}$ long (Figure 3 ). Behind the slit is an insulated back collector plate. The bottom stage of the collector is covered with commercial grade aluminum foil with a hole cut around the center slit. With this type of a collector, an oscilloscope image of the beam, over a limited mass range, can be obtained by modulating a $5 \mathrm{kV}, 3600 \mathrm{~Hz}$ signal 
on to the accelerating voltage. This sweeps the ion beam back and forth across the slit. The signal obtained from the back plate is a beam image which allows peak identification and precise beam focus.

For beam collection, the modulating voltage was removed and a high relative abundance stable isotope of the clement of interest allowed to pass through the slit and the current collected on the back plate monitored; all other isotopic species in the beam impinge on the aluminum collector foil. The current of the foil was also monitored. A change in the current ratio of the front to back plates gives an indication of defocus and/or instrument drift, should it occur. A permanent magnet was mounted directly bchind the collector plate to reduce electron losses from the collector via ion bombardment which would cause variable and erroneous current readings.

\subsection{Preseparation}

In order to avoid interference from the ${ }^{133} \mathrm{Cs}(\mathrm{n}, \alpha){ }^{130} \mathrm{I}$ and the ${ }^{235} U(n, f)^{13 X} I$ reactions, a pre-irradiation separation and concentration of the iodine from the sample matrix is cssential. Previous work in this laboratory has demonstrated that iodine can be quantitatively separated from biological matrices by combustion and collection on activated charcoal. The volatile materials trapped on the charcoal were then vacuum distilled into a quartz tube, sealed, and irradiated. In this work, tracer studies confirmed that iodine was distilled from a sample at $>800{ }^{\circ} \mathrm{C}$, and could be quantitatively trpped on activated charcoal. However, difficulty was encountered in quantitatively transferring the idoine from the charcoal to quartz tubing by vacuum distillation. A pressure increase in the quartz tube by desorption of other volatile materials, mostly 
organics, made the pumping time exceedingly long and rarely were the transfers quantitative. To eliminate this problem, it was found that the sample could be irradiated directly on the charcoal if the charcoal was first desorbed under vacuum at $850{ }^{\circ} \mathrm{C}$. Blank levels for a $250 \mathrm{mg}$ charcoal trap corresponded to 1 ess than $5 \times 10^{-14} \mathrm{~g}$ of ${ }^{129} \mathrm{I}$.

The preseparation procedure used is as follows:

A 2 gram sample was weighed into a combution boat and placed into the quartz combustion tube (Figure 4). A quartz tube, with a $250 \mathrm{mg}$ activated charcoal trap was fitted into a $19 / 38$ standard taper Teflon plug and the assembly mated with the end of the combustion tube. Oxygen as $2150 \mathrm{cc} / \mathrm{min}$ was passed over the sample and the sample ignited. After combustion stopped, the ash was heated to $800{ }^{\circ} \mathrm{C}$ for 10 minutes with a resistance furnace. The quartz tube containing the charcoal trap was removed, one end seated, evacuated, and the other end sealed. The charcoal trap, containing the volatile combustion products, was then vacuum sealed in the quartz ready for irradiation.

\subsection{Irradiation}

A11 neutron irradiations were carried out using the pneumatic transfer facilities RT-3 and RT-4 of the NBS Research Reactor. The thermal neutron fluxes obtained in these facilities are $5 \times 10^{+13}$ and $1.3 \times 10^{+13} \mathrm{n} \cdot \mathrm{cm}^{-2} \mathrm{~s}^{-1}$, respectively. $\mathrm{RT}-4$, with a copper-cadmium ratio of greater than 500 , was used for most of the irradiations as the production of ${ }^{126}$ I from the $(n, 2 n)$ reaction was greatly suppressed.

\subsection{Post-Irradiation Separation}

Following irradiation, the sample, plus added ${ }^{125}$ I used for yield calculations, was prepared in a known chemical state by distillation and reaction with silvered quartz wool. 
Onc requirement of radioisotope dilution as used for quantitation of mass separator results is that all isotopes used must be in the same chemical form. This is required because different chemical species of a given isotope will have different ionization efficiencies, resulting in different separation yields.

The following procedure was used for mass separation:

The outside of the irradiated quartz sample tube was washed with dilute HCl, cooled to liquid nitrogen temperatures, broken, and inserted into a quartz combustion tube similar to the one used for preseparation. $100 \mu 1$ of a standard ${ }^{125} \mathrm{I}$ solution and $5 \mathrm{mg}$ of non-active potassium iodide were added. Silvered quartz wool was packed into a threaded, open-end, graphite backloader sample holder designed specifically for this work (Figure 5). The sample holder was inserted into a $19 / 38$ standard taper joint on the quartz combustion tube. Oxygen was passed over the sample and the graphite ignited. The combustion tube was heated to $800{ }^{\circ} \mathrm{C}$ for 10 minutes, cooled, and the graphite sample holder removed. The threaded-end plug was inserted into the back of the sample holder and the assembly attached to the backloader delivery arm. The boat containing the sample was then inserted directly into the ion source oven and the system was evacuated to a pressure of $<5 \times 10^{-5}$ torr. Argon support gas was introduced to give a total arc chamber pressure of $2 \times 10^{-4}$ torr, the filament current increased and an arc struck in the arc chamber. The system was allowed to equilibrate for 5 minutes to eliminate sample outgassing effects as the arc chamber temperature increased to the operating temperature. After volatilization of the sample had begun, the argon support gas was reduced to a pressure of $\sim 8 \times 10^{-5}$ torr, and a beam of iodine extracted to give a beam current of $\sim 10 \mu \mathrm{A}$. 
The beam focus and intensity were optimized while monitoring the beam using the modulated high voltage, the top collector' plate, and oscilloscope. Following optimization of the instrument parameters, the $5 \mathrm{kV}$ modulated voltage was removed, the bottom collector plate raised into position, and the iodine-127 isotope positioned so as to completely pass through the central slit and fall onto the back collector plate. Visual observation is possible by turning off the room lights and observing the blue fluorescent 1 ines through the glass collector housing.

The oven temperature was raised slowly to $\sim 550{ }^{\circ} \mathrm{C}$ by conduction of heat from the arc chamber. During this time, the total beam current increased to $\sim 600 \mu \mathrm{A}$ and then as steady state temperature was achieved the beam current slowly dropped off. During this time, instrument parameters were periodically adjusted to maintain a maximum current ratio between the back and front collector plates.

The oven temperature was then raised slowly to maintain a stable iodine beam of $2300 \mu \mathrm{A}$ current. The separator was operated at this current with continuous monitoring of the current ratio between the front and back plate until all of the iodine was processed. An occasional increase in oven temperature was used to maintain the beam current. The time required for processing 15-20 mg of input sample under the conditions described was about 1 hour.

After a complete run, the collector plate was isolated from the rest of the system, brought to atmospheric pressure, and the aluminum collector foil removed. The mass region corresponding to mass 125,130 , and 132 were cut out and counted for yield and analysis respectively. 


\subsection{Counting}

Counting of the mass separated samples was performed using one of two systems. The first, used for photopeak identification and contamination checks, was an $84 \mathrm{~cm}^{3} \mathrm{Ge}(\mathrm{Li})$ detector coupled to a 2048 channel computer pulse height analyzer. All samples were counted for a minimum of 100 minutes on this system to check for any gamma photopeaks not associated with the decay of ${ }^{130} \mathrm{I}$. Selected samples containing $10 \mathrm{w}$ levels of ${ }^{129} \mathrm{I}$ were counted for 20 hours to obtain a good estimate of contamination.

The second counting system, used for high efficiency, and low background counting, was a $\beta-\gamma$ coincidence system. The system consisted of a Pilot-B $\beta$ scintillation disks optically coupled to a $2.54 \mathrm{~cm}$ diameter photomultiplier (PM) tube inserted into the well of a $12.5 \mathrm{~cm} \times 10 \mathrm{~cm}$ well type NaI(T1) gamma detector. The outputs of each detector were amplified and fed through the coincidence gate of a 400 channel pulse height analyzer. The $\beta-\gamma$ coincidence gamma spectrum was stored in the analyzer and summed from 0.1 to $3 \mathrm{MeV}$ for quantitation.

The main advantages of this system are background reduction and high efficiency counting. The normal background of the system is $\sim 0.1 \mathrm{c} / \mathrm{m}$ when shielded in a $5 \mathrm{~cm}$ thick mercury shield. The efficiency of the system is $>70 \%$ if the sample is deposited in a thin layer, relative to $\beta^{-}$absorption, directly onto the $\beta^{-}$scintillation wafer. Thin deposition of the sample was accomplished by using the scintillator material as the collector material of the mass separator in the mass 130 region (Figure 6). A $5 \mathrm{~mm}$ wide slit was cut in the normal aluminum foil target assembly, backed with the scintillator plastic and the beam in the mass 130 region was allowed to implant directly into the 
scintillator. The scintillator material was removed after a run, heat sealed between two clean scintillators, and optically coupled to the PM tube. The collection efficiencies of this procedure, at mass 125 implanted into aluminum compared to mass 130 implanted into Pilot-B, were checked and found to be equivalent to those totally collected on aluminum foil. This method of direct implantation of the isotope of interest into the $\beta$ scintillator has increased the counting efficiency by more than a factor of 2 over previous methods of counting.

\subsection{Standards}

One deficiency of past work on the determination of ${ }^{129}$ I has been the availability of adequate standards. NBS has recently issued as a Standard Reference Material (SRM 4949), a solution of ${ }^{129}$ I certified for absolute ${ }^{129}$ I activity. From this, solutions of absolute ${ }^{129}$ I concentrations were made by dilution and used for comparator standards. A11 quantitative results were related directly to SRM 4949.

\section{RESULTS AND DISCUSSION}

\subsection{Quantitation}

It was found in previous work with the mass separator that the most reliable method to quantify the percent recovery of the separated isotopes was to use radioisotope dilution (8). This technique involves the addition of a known quantity of a second isotope of the element of interest and assumes that the two isotopes behave in a similar fashion in the instrument.

The assumption of similar quantitative behavior must be verified. 
For the work with iodine, ${ }^{130} \mathrm{I}$ was the isotope used for analysis, as it was produced from the $(n, \gamma)$ reaction on ${ }^{129}$ I. Iodine-125 was chosen for yield quantitation because it has a long half-life, is not produced by neutron irradiation of stable iodine, and most importantly, it is two mass units removed from stable ${ }^{127} \mathrm{I}$. Past work with cadmium indicated significant losses in the collection of separated isotopes if they were adjacent to, or overlapping the mass region of large abundance stable isotopes (8).

This problem was investigated in detail with iodine isotopes and the results are given in Table 2 . Once again, the two isotopes adjacent to stable ${ }^{127}$ I show reduced yields. Usually, the low mass isotope has been most severely affected by sputtering losses due to slight asymmetry in the beam focus; however, in this work ${ }^{128} \mathrm{I}$ was separated in lowest yield. It was also noted that a measureable beam current could be detected in the mass-128 region. Since there are insufficient ${ }^{128} \mathrm{I}$ ions in the beam to be measured by current collection, it is believed that the hydride ion,

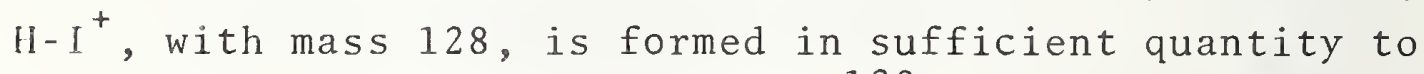
interfere with the collection of ${ }^{128} \mathrm{I}$. It was also noted that the intensity of the peak at mass-128 decreased in amplitude, relative to mass-127 during a given run. This is consistent with the proposed hydride ion interference in that trace water, from which $\mathrm{H}^{+}$ions can be found in the ion source, is quickly evaporated out of the samples at operating temperature. Although hydride ion formation is only of passing interest to this analysis, it is important to note for any work where the isotope of interest is a stable mass plus one.

Iodine-126 also gave low collection efficiencies, relative to ${ }^{125} \mathrm{I}$ and ${ }^{130} \mathrm{I}$. In this case, however, the loss in 
yield was similar to that seen with cadmium isotopes which were adjacent to a stable isotopic mass and can be attributed completely to sputtering losses from overlapping ${ }^{127} \mathrm{I}$.

In experiments where known quantities of ${ }^{125_{I}}$ and ${ }^{130} \mathrm{I}$ tracers were added, yields were found to be equivalent for these isotopes. Since it was essential that this be the case, numerous runs, under various instrumental operation conditions, were carried out and in all cases yields were found equivalent within the errors due to radioisotopic counting statistics (Table 2).

\subsection{Analytical}

With a11 of the individual components of the analytical scheme worked out and tested with tracers, analyses were conducted for ${ }^{129} \mathrm{I}$ content of two natural samples. One sample was a freeze-dried hog thyroid, obtained from the U. S. Department of Agriculture, which represented samples naturally enriched in total iodine. The second was a freeze-dried filleted albacore tuna fish sample, which is currently being developed at NBS as a trace element standard and on which numerous homogeneity studies have been conducted.

Samples were weighed into a quartz tube $10 \mathrm{~mm}$ in I.D., $15 \mathrm{~cm}$ long. The entire tube was inserted into the quartz combustion tube and the pre-irradiation separation carried out as described in section 2.2 .

Following preseparation, an iron foil flux monitor was attached to the sealed quartz tube containing the distillates. The unit was sealed in a polyethylene "rabbit" and irradiated in the NBSR pneumatic transfer facility RT-4 for 12 hours at a thermal neutron flux of $1.3 \times 10^{13} \mathrm{n} \cdot \mathrm{cm}^{-2} \mathrm{~s}^{-1}$. 
After irradiation, the sample was allowed to decay for 6 hours to reduce ${ }^{128} \mathrm{I}$ and other short half-lived activity. The flux monitor was removed and possible exterior contamination of the quartz vial removed by acid washing. The sample was then frozen in liquid nitrogen to condense any gascous material, the quartz vial broken open into a combustion boat, and a $100 \mathrm{ml}$ aliquot of the ${ }^{125} \mathrm{I}$ standard tracer solution along with $10 \mathrm{mg}$ of potassium iodine carrier added. The post irradiation separation into mass components was carricd out as described in section 2.4 .

Mass regions 125,130 , and 132 were isolated and each was counted using the Ge(Li) gamma detector to determine if any interfering isotopes were present. The ${ }^{125}$ I was counted on a low energy photon system (LEPS) using the iodine $X-$ ray for quantitation of yields. If no contamination was present, the ${ }^{130} \mathrm{I}$ was counted for from 100 to 1,000 minutes using the $\beta-\gamma$ coincidence system. To insure against fission product interference, the mass -132 region was also counted on every analysis. If ${ }^{132}$ I were found,its only source could be from fission production during neutron irradiation. Thus, using the mass separator, an additional advantage was realized. The absence of ${ }^{132} \mathrm{I}$ in the mass-132 region verified the effectiveness of the sample preseparation procedure.

Initial analyses were carried in a specially cleaned fume hood in a normal working laboratory. One run each was carried out on the hog thyroid and tuna fish. Thë analyses were preceded and followed by blank runs where the entire procedure was carried out with empty cleaned equipment (boats, combustion tubes, charcoal traps, etc.). The results are shown in Table 3 . As can be seen, the blank, with its associated variability, was the major limitation on 
the analytical system. One major problem was that ${ }^{129}$ I standard solutions had been prepared in an adjacent laboratory area and thus low level contamination of the entire laboratory area was possible.

In light of the severe blank problem, the entire sample preparation and preseparation aparatus was cleaned and moved into a class 100 clean room. All sample manipulations were carried out in the clean room. Only after the preseparated samples were sealed in quartz were they removed from the clean room facility. Analysis on the hog thyroid and tuna standard were repeated and a significant reduction in blank observed. The results are given in Table 4. As can be seen, blank levels were reduced by almost three orders of magnitude by adopting clean room operation. These blank levels were derived from variations in background counting statistics and thus could be lowered by subjecting the samples to higher neutron doses. For these samples, however, that was not necessary. The samples contained significant activity above background levels. These analyses, although limited in number, have conclusively demonstrated the ability of determining as 1 ittle as $10^{8}$ total atoms of ${ }^{129} \mathrm{I}$ in real biological matrices. This sensitivity is extremely important if samples of biological origin, other than iodine concentrators such as kelp and thyroid, are to be analyzed.

\subsection{Interferences and Errors}

A major source of possible error, when $\beta-\gamma$ coincidence sum counting is used, is the contamination of the mass130 region with other isotopic species. This may occur cither by molecular ion formation or by alteration of ionic species within the magnetic sector by ionic reflection off walls and by gaseous collisions. Molecular ion 
formation which was discussed in length in a previous publication (8) was not found to be a contaminant here. Contamination of a given mass region by isotopes more than ten mass units removed from the mass of interest has been measured and was found to be less than $10^{-6}$. Norma11y a separation specificity that great would be more than adequate to reduce contaminants to a negligible level. However, in this work, the levels desired are in the $10^{8}$ $10^{9}$ atom range. Thus, if the sample contains $10^{6}$ or greater activity from other volatile isotopes, general contamination of the collector foil may occur. This type of contamination is believed to be from low angle scattering of the beam off the walls of the drift section of the instrument. Mass species greatly different from that being collected will fall in regions on the side wall of the drift section of the instrument and during a run, some of these species will be reintroduced into the beam plasma by reflection. These ions will have a broadened energy profile, not monoenergetic like the accelerated ions. If this occurs within the magnetic region of the drift tube, the scattered ions will be deflected in a continuous broad band across all surfaces, including the collector foil. This type of contamination was observed for the first time in the lowest level samples of tuna fish. Bromine-82 was observed in a 40 hour Ge(Li) count taken to give a good estimate of possible contamination. The contamination occurred because the activity level from $\sim 10 \mathrm{ppm}$ bromine in the tuna sample gave greater than $10^{6}$ times the activity derived from ${ }^{129} \mathrm{I}$. The activity level found from $82 \mathrm{Br}$ would account for an estimated $10 \%$ positive bias in the ${ }^{129} \mathrm{I}$ analysis if $\beta-\gamma$ coincidence sum counting were used. 
The magnitude of the contamination can be reduced by using a smaller region of the collector foil for analysis. Ninetyfive percent of the ${ }^{130} \mathrm{I}$ mass is deposited in a 1 ine $1 \mathrm{~mm}$ in width. Currently, $8 \mathrm{~mm}$ of collector foil are removed and counted to insure complete inclusion of the desired isotope. By exactly locating the ${ }^{130} \mathrm{I}$ mass 1 ine to the nearest $0.1 \mathrm{~mm}$ and reeucing the width of collector foil counted to $\sim 1 \mathrm{~mm}$, an 8 -fold reduction in the ${ }^{82} \mathrm{Br}$ activity could be realized.

Interference from ${ }^{82} \mathrm{Br}$ or any other isotope has not been detected in the hog thyroid samples or in any of the blank runs. Investigations of this type of contamination is continuing and a more fundamental solution is being sought, such as an improved baffling system for the instrument flight tube.

The second most important error in these analyses is that of the blank. The use of the class 100 clean room was found to be essential to the success of this project. More work should be devoted to establish the actual blank level and its main contributing factors. With detailed knowledge of blank sources, more control can be applied to insure against sporatic high level contamination of the sample before it is processed.

Contamination of the sample from fission products or iodine126 was not a problem using mass separation. Iodine-130 is shielded from fission products formation by ${ }^{130} \mathrm{Te}$. The direct fission yield is so small as not to be of concern, even in this work. Other iodine isotopes and possible interferences from secondary reactions are removed by the mass separation step and are thus no problem. 
The ${ }^{126} \mathrm{I}$ did not offer interference as it was 4 mass units removed from ${ }^{130} \mathrm{I}$ used for analysis and overlap amounted to $<10^{-5}$ times the activity in the primary mass 1ine. In no case was ${ }^{126} \mathrm{I}$ found as an interference in the mass-130 region.

The final problem which must be considered as an interference is triple neutron capture of stable ${ }^{127} \mathrm{I}$. Although the probability of triple neutron capture is very small, it must be considered, especially when very high flux reactors are used. Edwards et al have calculated and experimentally measured this interference (7). Based on their data, under the irradiation conditions used here, the formation of ${ }^{130} \mathrm{I}$ from ${ }^{127} \mathrm{I}(3 \mathrm{n}, \gamma)$ was not detectable.

Other errors were derived from those normally associated with neutron activation and will not be repeated here.

\section{CONCLUSIONS AND PROPOSED RESEARCH}

The results of this work have demonstrated the feasibility of measuring ${ }^{129} \mathrm{I}$ at the $10^{+8}-10^{+9}$ atom level using an electromagnetic mass separator. This is a substantial improvement over previous work and allows the measurement of ${ }^{129} \mathrm{I}$ in biological samples other than those which naturally concentrate iodine.

With the analytical procedure for the determination of ${ }^{129} \mathrm{I}$ completed, it would be extremely valuable to devote the necessary time and effort to obtain a reliable ${ }^{129}$ I value in one of the NBS biological SRM's. A particularly good choice would be the new tuna fish standard since the 129 I level is at the lower measurable range of conventional procedures for determining ${ }^{129} \mathrm{I}$ and other 
members of the scientific community could use this standard as a control for their best possible work. The effort involved in getting a reliable value of ${ }^{129} \mathrm{I}$ in such a standard material would also yield a better understanding of the repeatability and total system error in the described procedure.

\section{ACKNOWLEDGMENT}

This research was supported by the Defense Advanced Research Projects Agency of the Department of Defense and was monitored by Hq USAF (AFTAC/TRE), Patrick AFB, FL 32925 under Project Authorization VT/3416. 


\section{BIBL IOGRAPHY}

1. B. C. Purkayastha and G. R. Martin, Can. J. Chem $\underline{34}$, 293 , (1956).

2. R. R. Edwards, Science 137, 851 (1962).

3. M. H. Studier, C. Postmis Jr., J. Mech, R, R. Walters and E. N. Sloth, J. Inorganic Nucl. Chem. 34, 755 (1962).

4. R. C. Koch and B. Keisch, L Analyse par Radioactivation et ses Applications Aux Sciences Biologiques, Presses Universitaires de Fance, 108, B1vd, Saint-Germain, Paris, 6E, 47-68 (1964). (English). Pittsburgh, Pa.

5. G. Buzzel1i, Anal. Chem., 36, 1973 (1964).

6. B. Keisch, R. C. Koch, and A. S. Levine, Proceedings 1965 International Conference. Modern Trends in Activation Analysis, College Station, Texas, 284-290, Apri1 19-22, 1965 .

7. R. R. Edwards and P. Rey, NYO-3624-3, 30p., 1967, Department of Chemistry, Carnegie-Me11on Univ., Pittsburg, $\mathrm{Pa}$.

8. H. L. Rook, P. D. LaFleur, and J. E. Suddueth, NucZ. Instrum. Methd., Accepted for publication, September 1973 .

9. J. H. Freeman, Nucl. Instrum. Methad, 38, 97 (1965).

Disclaimer:

Certain commercial equipment, instruments, or materials are identified in this paper in order to adequately specify

the experimental procedure. In no case does such identification imply recommendation or endorsement by the

National Bureau of Standards, nor does it imply that the material or equipment identified is necessarily the best available for the purpose. 


$$
\text { Table } 1
$$

Mass Separator Yield as a

Function of Arc Current

Isotope

Arc Current

$\underline{\text { Percent Yield }}$

$125 \mathrm{I}^{\mathrm{a}}$

$125_{\mathrm{I}} \mathrm{a}$

$125_{\mathrm{I}} \mathrm{b}$

$125 \mathrm{I}^{\mathrm{b}}$

$125_{\mathrm{T}}^{\mathrm{b}}$

$130 \mathrm{I}$

$125 \mathrm{I}^{\mathrm{b}}$

$125_{\mathrm{I}}^{\mathrm{b}}$
2.0

2.1

3.2

3.2

4.0

$4 \cdot 0$

4.3

4.3
8.3

8.8

19.5

20.6

23.6

22.0

34.0

31.8

a Run made with original backloader

b Run made with modified ion source power supply 
Table 2

Separation Yields as a Function of Mass Iodine Isotopic Mass

\begin{tabular}{|c|c|c|c|c|}
\hline Run & 125 & 126 & 128 & 130 \\
\hline 1 & & 6.3 & & \\
\hline 2 & & 7.2 & & \\
\hline 3 & & 5.2 & 1.4 & \\
\hline 4 & & 3.6 & 1.1 & \\
\hline 5 & 19.5 & 3.4 & & \\
\hline 6 & 21.7 & 5.4 & & 22.0 \\
\hline 7 & 14.4 & & & 14.0 \\
\hline 8 & 33.9 & & & 31.2 \\
\hline 9 & 23.6 & & & 22.0 \\
\hline 10 & 17.5 & & & 17.5 \\
\hline 11 & 17.7 & & & 18.1 \\
\hline 12 & 17.4 & & & 18.0 \\
\hline
\end{tabular}

Table 3

System Blank for Norma1 Laboratory Operation

\begin{tabular}{|c|c|c|}
\hline Sample & Wt Sample & $\begin{array}{l}\text { Concentration } \\
\mathrm{g} \quad{ }^{129} \mathrm{I} / \mathrm{g} \text { sample }\end{array}$ \\
\hline Blank & $\equiv 1.0$ & $2.39 \times 10^{-10}$ \\
\hline Tuna & $0.973 \mathrm{~g}$ & $1.73 \times 10^{-11}$ \\
\hline Hog Thyroid & $2.131 \mathrm{~g}$ & $4.19 \times 10^{-11}$ \\
\hline Blank & $\equiv 1.0$ & $2.51 \times 10^{-11}$ \\
\hline
\end{tabular}


Table 4

${ }^{129}$ I Analytical Results

Sample

Blank

Hog Thyroid

Tuna

Tuna

Blank
Sample Wt. (g)

1.0

1.91

1.22

1.53

1.0
Concentration $\mathrm{g}^{129} \mathrm{I} / \mathrm{g}$ sample

$8.5 \times 10^{-14}$

$9.0 \times 10^{-12}$

$9.3 \times 10^{-13}$

$7.9 \times 10^{-13}$

$4.5 \times 10^{-14}$ 


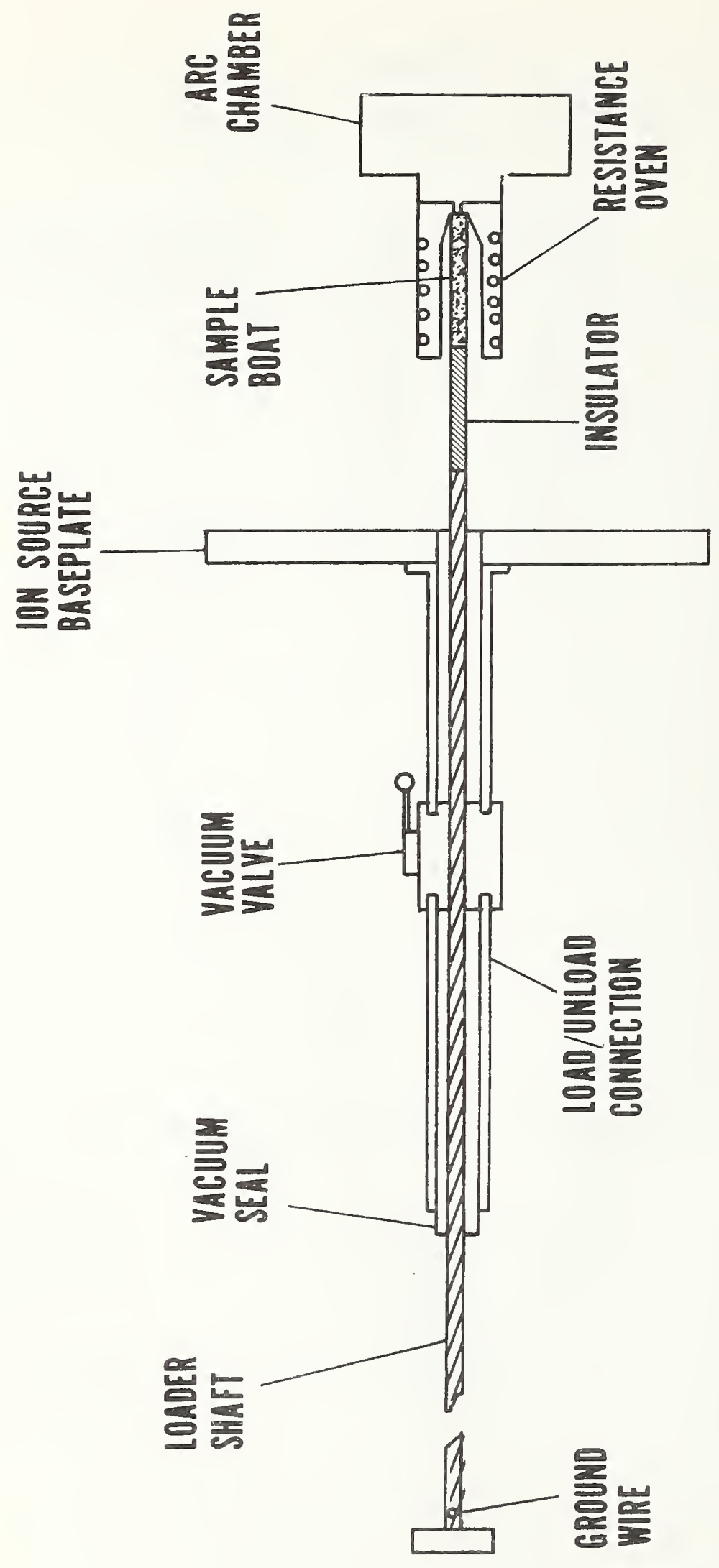

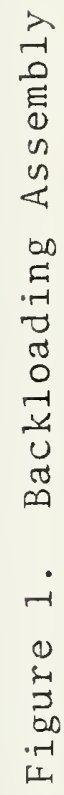




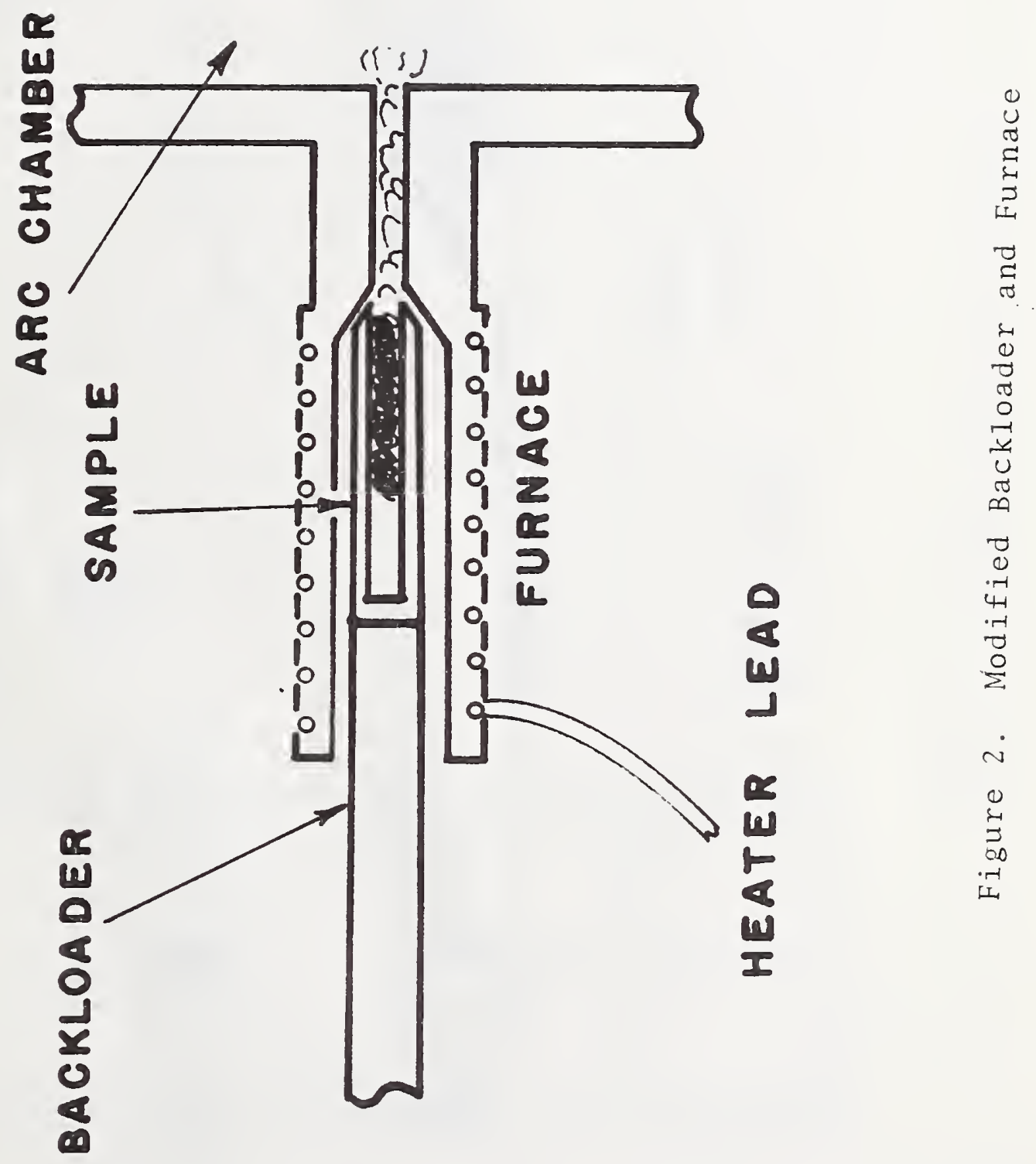




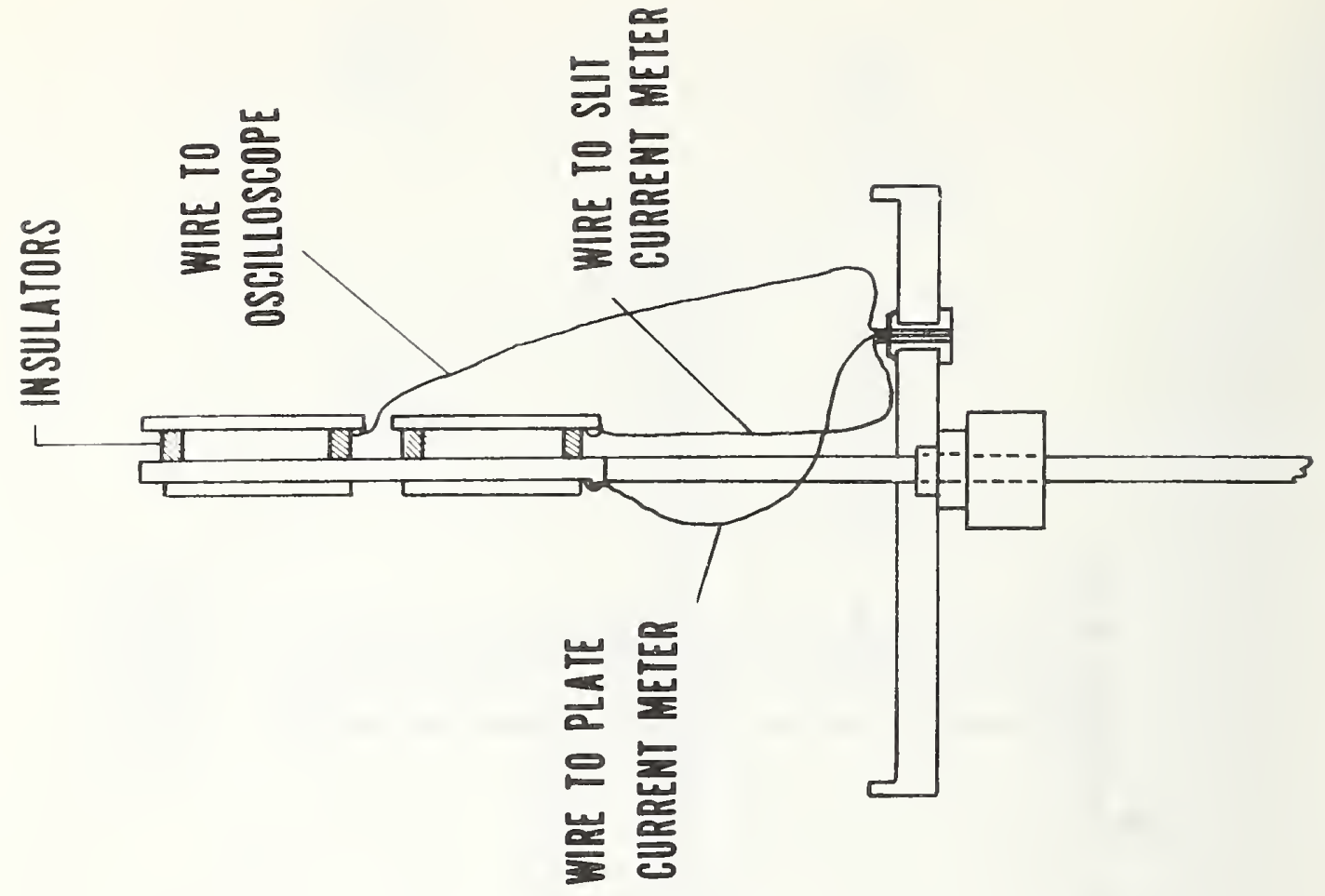

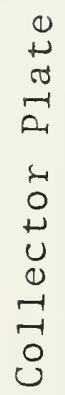

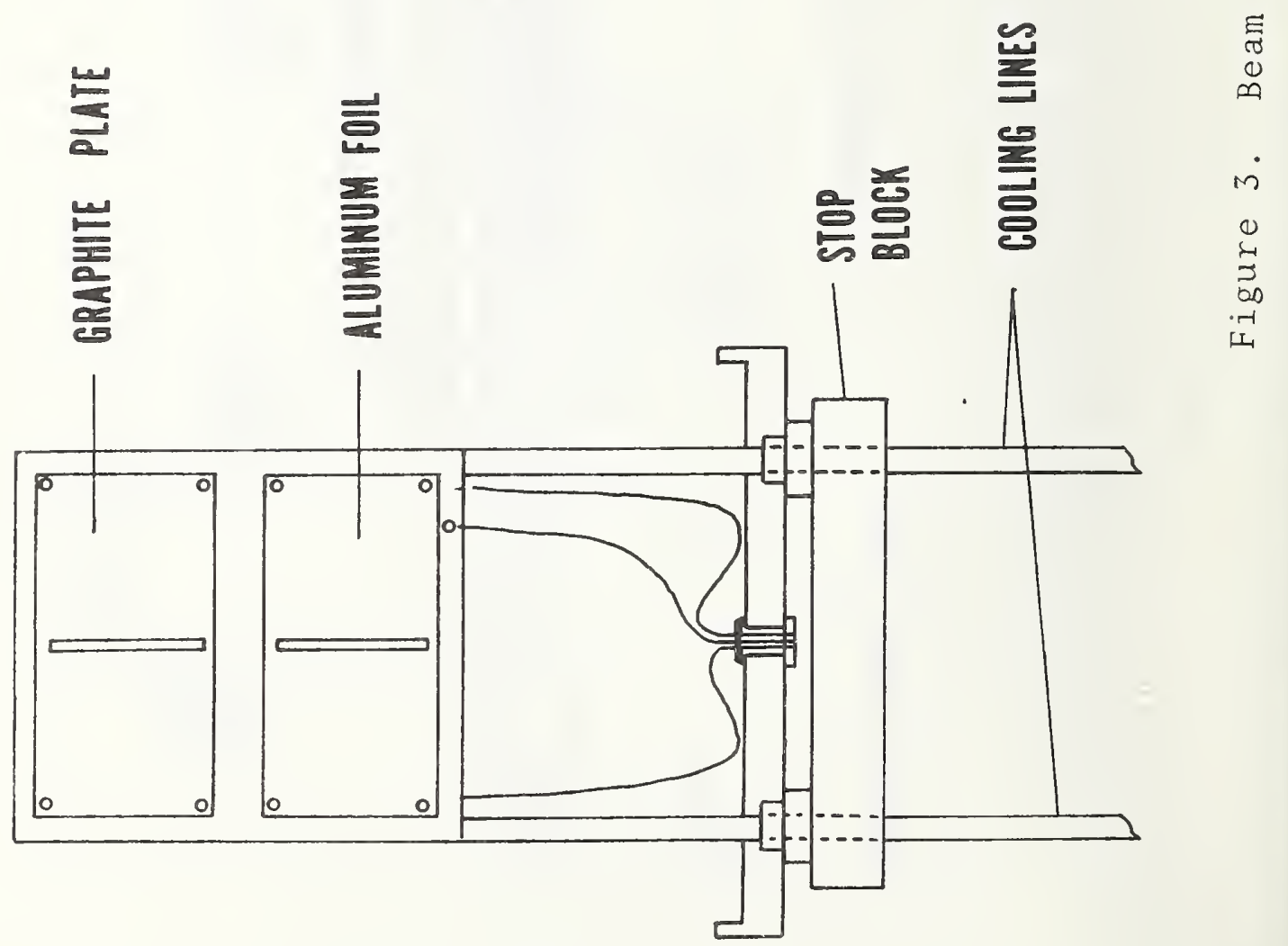




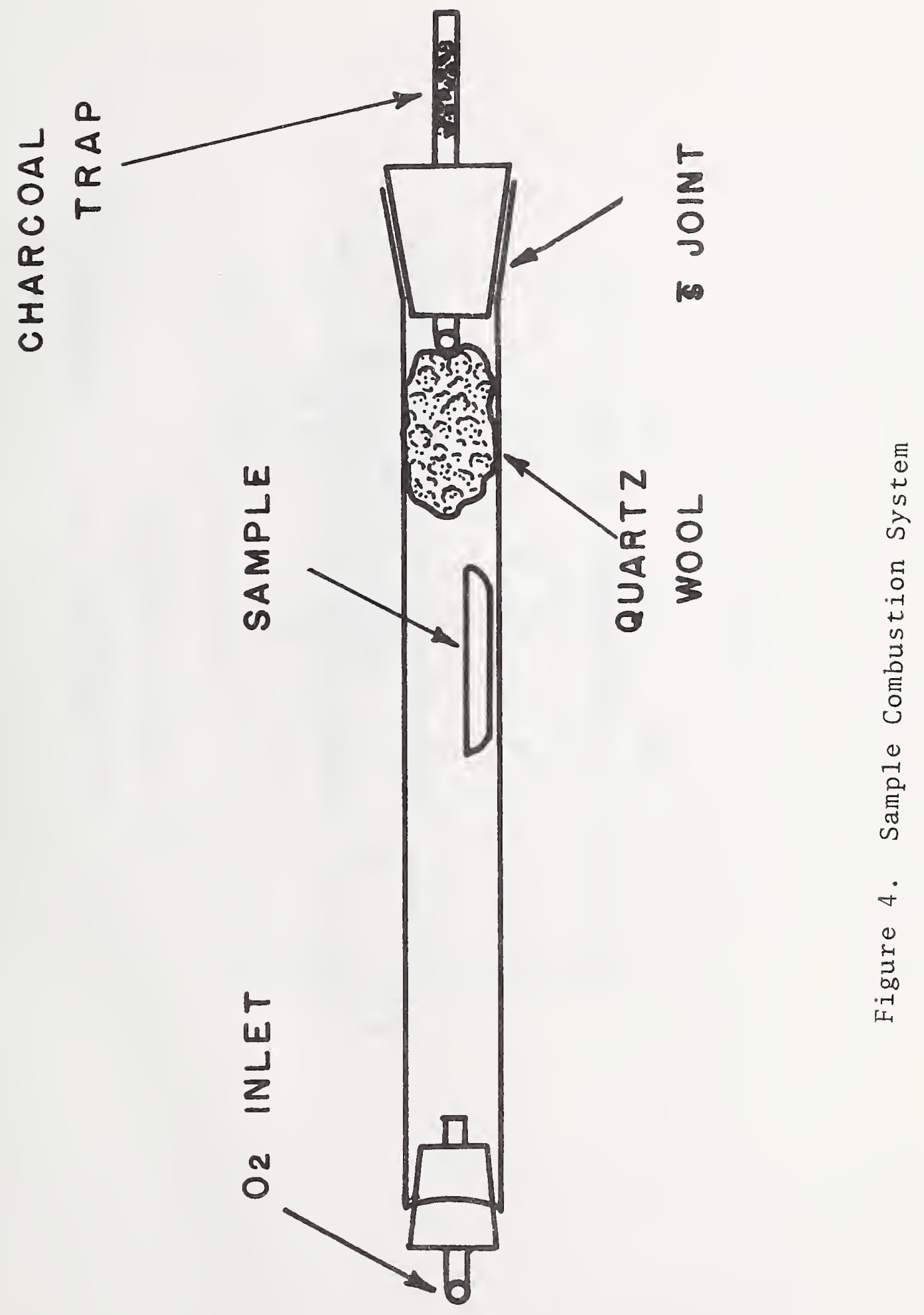




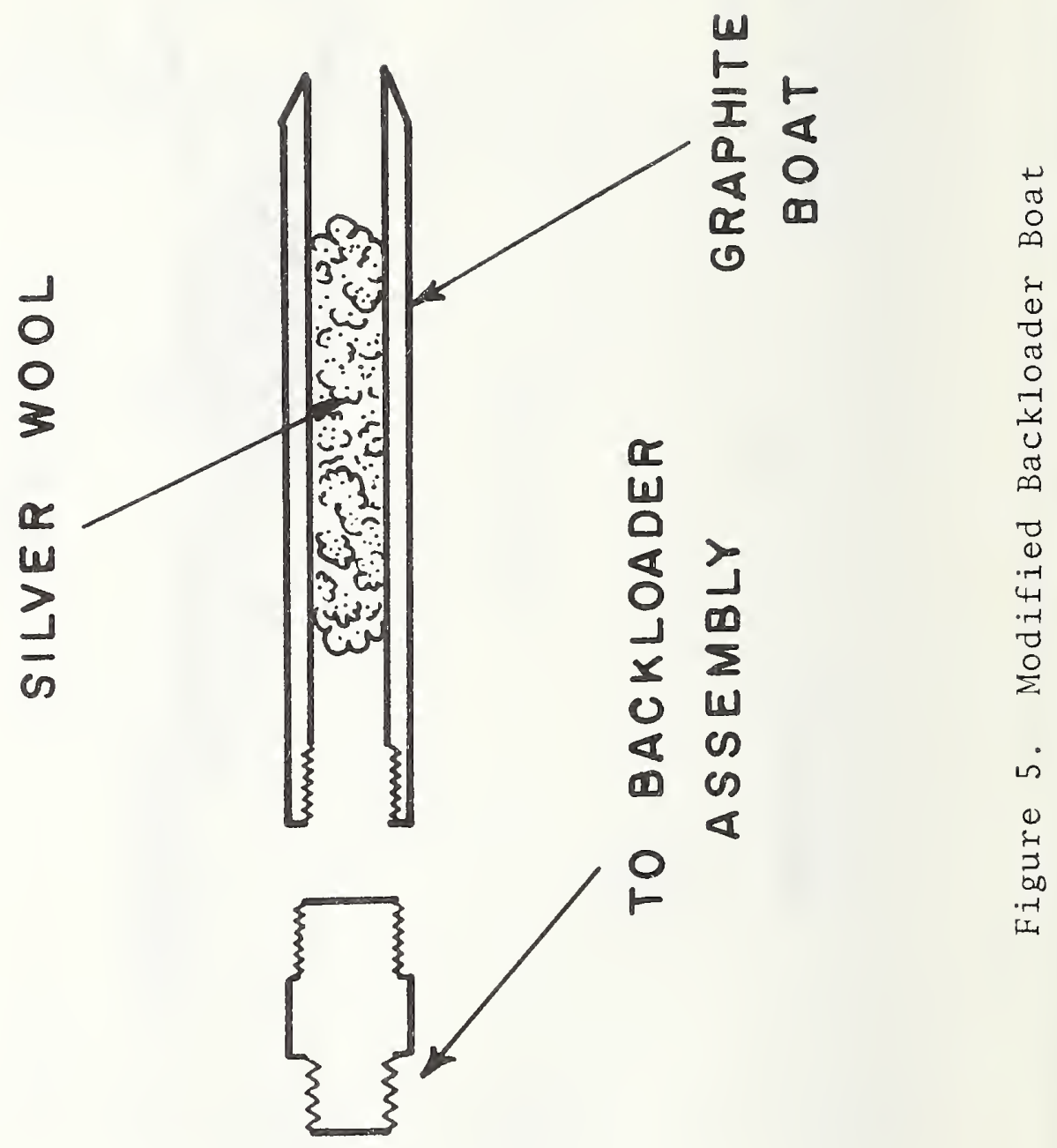




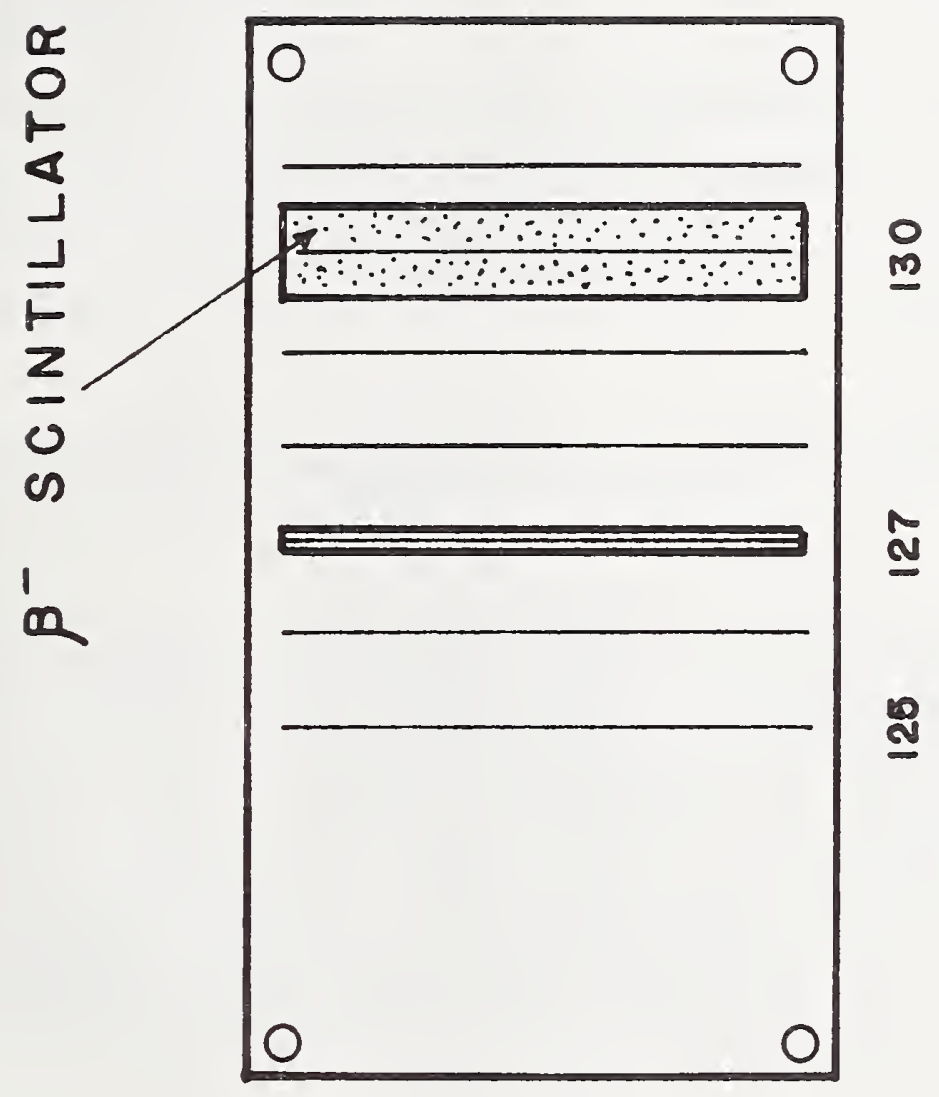

O 

NBS.114A (REV. 7.73)

\begin{tabular}{|c|c|c|}
\hline $\begin{array}{l}\text { U.S. DEPT. OF COMM. } \\
\text { BIBLIOGRAPHIC DATA } \\
\text { SHEET }\end{array}$ & $\begin{array}{l}\text { 1. PUBLICATION OR REPORT NO. } \\
\text { NBSIR } 74-502\end{array}$ & 3. Recipient's Accession No. \\
\hline \multirow{3}{*}{\multicolumn{2}{|c|}{$\begin{array}{l}\text { 4. TITLE AND SUBTITLE } \\
\text { The Determination of Iodine-129 at Natural } \\
\text { Levels Using Neutron Activation and Isotopic } \\
\text { Separation }\end{array}$}} & 5. Publication Date \\
\hline & & JuIy 1974 \\
\hline & & 6. Performing Organization Code \\
\hline \multicolumn{2}{|c|}{$\begin{array}{l}\text { 7. AUTHOR(S) } \\
\text { Harry L. Rook, James E. Suddueth and Donald A. Becken }\end{array}$} & $\begin{array}{l}\text { 8. Performing Organ. Report No. } \\
\text { NBSIR } 74-502 \\
\end{array}$ \\
\hline \multirow{2}{*}{\multicolumn{2}{|c|}{$\begin{array}{l}\text { 9. PER FORMING ORGANIZATION NAME AND ADDRESS } \\
\text { NATIONAL BUREAU OF STANDARDS } \\
\text { DEPARTMENT OF COMMERCE } \\
\text { WASHINGTON, D.C. } 20234\end{array}$}} & $\begin{array}{l}\text { 10. Project/Task/Work Unit No. } \\
310-5484\end{array}$ \\
\hline & & $\begin{array}{l}\text { 11. Contract/Grant No. } \\
\text { AFTAC Auth. No. } \\
\text { VT/3416 }\end{array}$ \\
\hline \multirow{3}{*}{\multicolumn{2}{|c|}{$\begin{array}{l}\text { 12. Sponsoring Organization Name and Complete Address (Street, City, State, ZIP) } \\
\text { Defense Advanced Research Projects Agency } \\
\text { Office of the Secretary of Defense } \\
\text { 1400 Wilson Blvd., Arlington, VA } 22209\end{array}$}} & 13. Type of Report \& Period \\
\hline & & Final Report \\
\hline & & 14. Sponsoring $A$ \\
\hline
\end{tabular}

15. SUPPLEMENTARY NOTES

16. ABSTRACT (A 200-word or less factual summary of most significant information. If document includes a significant bibliography or literature survey, mention it here.)

Iodine-129 levels have been published for biological matrices that naturally accumulate iodine such as animal thyroid and kelp. However, published procedures have insufficient sensitivity to determine $129 \mathrm{I}$ in other environmental and biological species. A unique procedure has been developed for the determination of 129 I which couples neutron activation with mass separation. The procedure results in a significant improvement in sensitivity, thus allowing analyses to be performed on a variety of matrices which heretofore had not been investigated. Method development and analytical procedures are presented and analytical resutis at the $10^{-13}-10^{-14}$ gram 129 I level are given.

17. KEY WORDS (six to twelve entries; alphabetical order; capitalize only the first letter of the first key word unless a proper name; separated by semicolons)

Improved limits of detection; iodine-129; isotopic separation; neutron activation

18. AVAILABILITY Unlimited

$\underline{X X}$ For Official Distribution. Do Not Release to NTIS

Order From Sup. of Doc., U.S. Government Printing Office

Washington, D.C. 20402, SD Cat. No.C13

Order From National Technical Information Service (NTIS) Springfield, Virginia 22151

\begin{tabular}{|l|c|}
\hline $\begin{array}{l}\text { 19. SECURITY CLASS } \\
\text { (THIS REPURT) } \\
\text { UNCL ASSIFIED }\end{array}$ & 21. NO. OF PAGES \\
\hline $\begin{array}{l}\text { 20. SECURITY CLASS } \\
\text { (THIS PAGE) } \\
\text { UNCLASSIFIED }\end{array}$ & 29 \\
\hline \multicolumn{1}{|l}{ 22. Price } \\
\hline
\end{tabular}






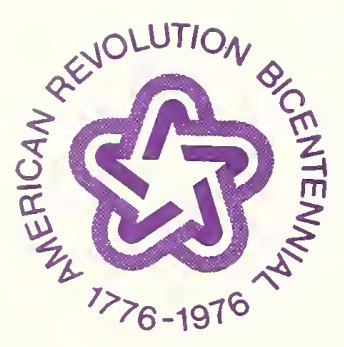


[19] 


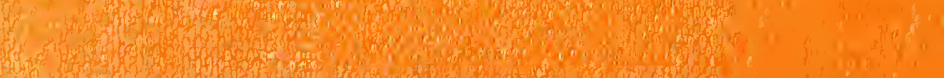

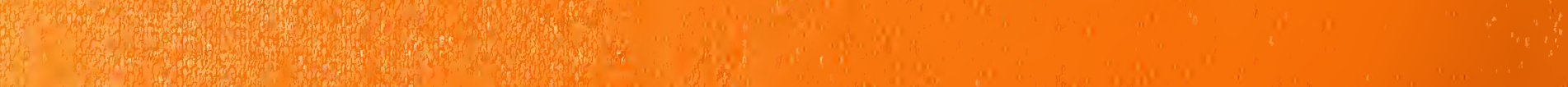

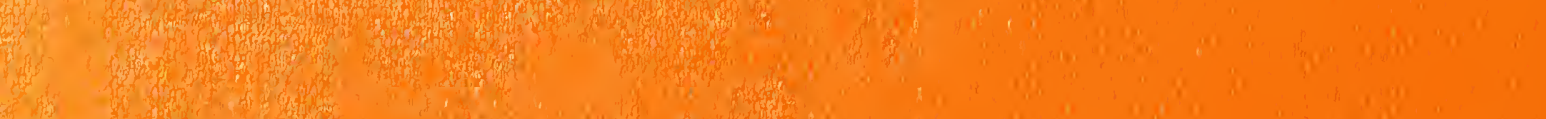

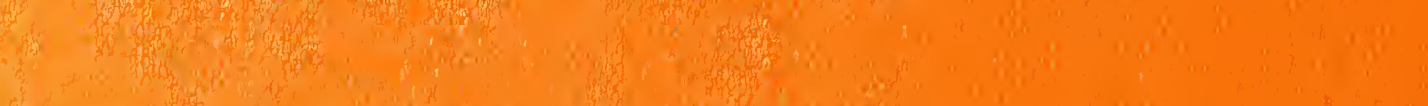

f.

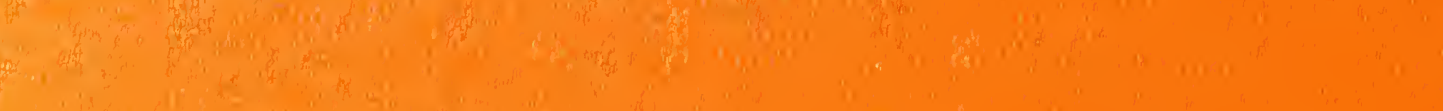

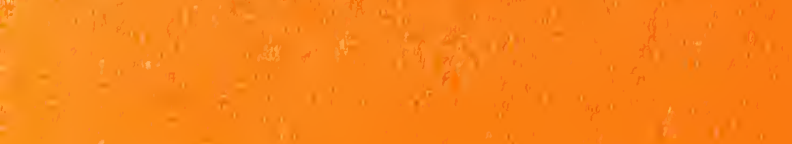

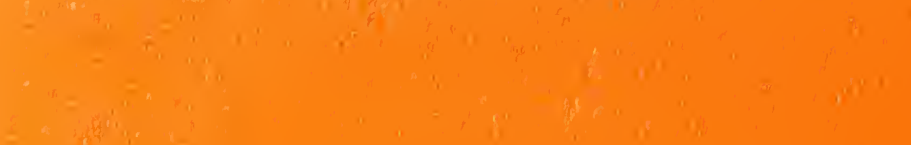

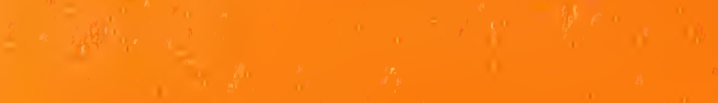

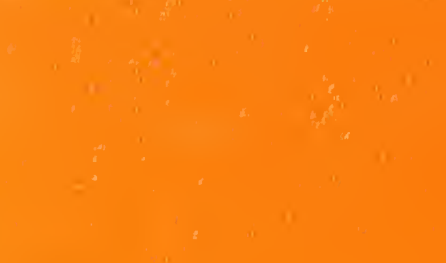

if
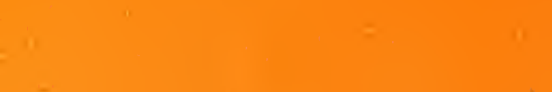

$x=$

$+\infty$

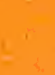

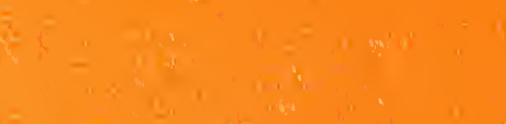

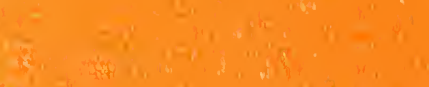

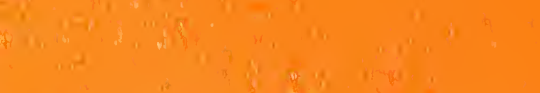

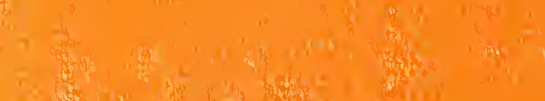

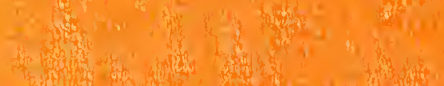

$x_{0}^{3}$ 